\title{
Article \\ CoNiZn and CoNiFe Nanoparticles: Synthesis, Physical Characterization, and In Vitro Cytotoxicity Evaluations
}

\author{
Sima Alikhanzadeh-Arani ${ }^{1,2}$, Mohammad Almasi-Kashi ${ }^{3}$, Saman Sargazi ${ }^{4} \oplus$, Abbas Rahdar ${ }^{5, *} \mathbb{}$, \\ Rabia Arshad ${ }^{6}(\mathbb{D})$ and Francesco Baino $7, * \mathbb{D}$ \\ Farhangian University, Tehran 19396-14464, Iran; s.alikhanzadeh@cfu.ac.ir \\ 2 Institute of Nanoscience and Nanotechnology, University of Kashan, Kashan 87317-51167, Iran \\ 3 Department of Physics, University of Kashan, Kashan 87317-51167, Iran; almac@kashanu.ac.ir \\ 4 Cellular and Molecular Research Center, Resistant Tuberculosis Institute, Zahedan University of Medical \\ Sciences, Zahedan 98167-43463, Iran; sgz.biomed@gmail.com \\ 5 Department of Physics, University of Zabol, Zabol 98613-35856, Iran \\ 6 Department of Pharmacy, Quaid-i-Azam University, Islamabad 45320, Pakistan; rabia.arshad@bs.qau.edu.pk \\ Institute of Materials Physics and Engineering, Department of Applied Science and Technology, \\ Politecnico di Torino, 10129 Turin, Italy \\ * Correspondence: a.rahdar@uoz.ac.ir (A.R.); francesco.baino@polito.it (F.B.)
}

Citation: Alikhanzadeh-Arani, S.;

Almasi-Kashi, M.; Sargazi, S.;

Rahdar, A.; Arshad, R.; Baino, F.

CoNiZn and CoNiFe Nanoparticles: Synthesis, Physical Characterization, and In Vitro Cytotoxicity Evaluations Appl. Sci. 2021, 11, 5339. https:// doi.org/10.3390/app11125339

Academic Editor: Yurii K. Gun'ko

Received: 2 May 2021

Accepted: 7 June 2021

Published: 8 June 2021

Publisher's Note: MDPI stays neutral with regard to jurisdictional claims in published maps and institutional affiliations.

Copyright: (c) 2021 by the authors. Licensee MDPI, Basel, Switzerland. This article is an open access article distributed under the terms and conditions of the Creative Commons Attribution (CC BY) license (https:/ / creativecommons.org/licenses/by/ $4.0 /)$.

\begin{abstract}
The polyol method has been used to synthesize CoNiFe and CoNiZn alloy nanoparticles (NPs). The magnetic characteristics of the products have been measured by vibration sample magnetometry (VSM) analysis. At the same time, the microstructure and morphology were inspected by X-ray diffraction (XRD) and scanning electron microscopy (SEM), respectively. Magnetic measurement of samples by the VSM indicated that samples have soft ferromagnetic behavior. Spherical-shaped grains for samples were confirmed by the SEM. MTT (3-(4,5-Dimethylthiazol-2-yl)2,5-diphenyltetrazolium bromide) and lactate dehydrogenase (LDH) assays were used to determine the cytotoxic effects of the synthesized NPs. Cytotoxic evaluations showed that treatment with 25 to $400 \mu \mathrm{g} / \mathrm{mL}$ of CoNiZn and CoNiFe NPs exerted a significant time- and concentration-dependent toxicity in MCF7 and HUVEC cells and markedly enhanced the LDH leakage after $48 \mathrm{~h}$ of exposure ( $p<0.05$ compared with untreated cells). Furthermore, NPs with concentrations higher than $12.5 \mu \mathrm{g} / \mathrm{mL}$ induced evident morphological changes in the studied cell lines. Treatment with $12.5 \mu \mathrm{g} / \mathrm{mL}$ of CoNiZn and CoNiFe NPs was safe and did not affect normal human cell survival. The results of in vitro cytotoxicity assessments show promise in supporting the suitability of the synthesized NPs to build high-performance theranostic nanoplatforms for simultaneous cancer imaging and therapy without affecting normal human cells.
\end{abstract}

Keywords: nanomaterials; cytotoxicity; nanoparticles; magnetic; in vitro; biomedical applications; cancer treatment

\section{Introduction}

Cancer is the deadliest disease in the world and is responsible for endangering human survival. Owing to complications, high cost for treatment, and poor theranostics, it causes around $\sim 70 \%$ mortality in developing and under-developed countries [1]. Theranostics is considered a concept of integrating cancer therapy and imaging into a unique platform to overcome the obstacles in modern healthcare [2]. The diagnostic aspect of theranostics is mainly focused on imaging mechanisms by the use of various contrast agents. A large number of studies have been devoted to investigating the biocompatibility of magnetic NPs for their use as contrast agents for magnetic resonance imaging (MRI) [3]. Moreover, nanomaterials have shown great promise in facilitating the treatment of a variety of diseases [4] and have been applied in the field of oncology in the same way as in other branches of biomedical nanotechnology. However, careful design and tailoring of the production process are necessary to control the size and shape of nanomaterials in order to 
modulate their properties, avoid toxicity, and achieve high cost-effectiveness as well as ease of synthesis [5].

Basically, nanoporous noble metal-based alloys have been suggested for their application in electrocatalysts in fuel cells and electrochemical sensors [6]. On the other hand, several modifications in the synthesis of nanocarriers for improving therapeutic efficacy and theranostics are still to be done in the future. However, we observed that metallic alloybased ternary nanoparticles are gaining significant importance in biological applications, such as bio-imaging, drug delivery, bio-catalysis, biosensing, and overall therapeutics [4], while a firm understanding of their biocompatibility is still missing. It has been reported that some metallic NPs have a wide range of potential reprotoxic effects depending on their composition, synthesis method, and administration route [7,8]. In this respect, silver-gold alloy NPs biofabricated by fungal xylanases exhibited potent biomedical applications due to their antibacterial, antifungal, and antioxidant effects [9]. Recently, NPs of gold, silver, iron oxide and gadolinium have been widely studied with the aim to discover an appropriate one with the fewest cytotoxicity against normal human cells. These NPs can be used in theranostics as contrast agents for MRI to highlight diseased tissue/cells in contrast to normal tissue/cells.

Furthermore, it has been established that various properties of metallic NPs affect their toxic potential [3]. Some magnetic alloys, including the combination of nickel and chromium $\left(\mathrm{Ni}_{1-x} \mathrm{Cr}_{x}\right)$ particles in different concentration ratios, have been investigated as thermoseeds for localized and self-controlled cancer treatment [10]. Nickel and copper magnetic alloys containing $71 \%$ nickel and 29\% copper (by weight) were also proposed for anticancer applications [11]. Specifically, these self-regulated magnetic alloys were used in magnetic hyperthermia for cancer treatment [12]. Furthermore, $\mathrm{CuFeSe}_{2}$ nanocrystals showed super-magnetism and effective reduction for X-rays, as well as excellent water solubility, colloidal stability, biocompatibility, and multi-functionalized groups [13]. These features further enabled these ternary alloys for multi-model imaging, MRI, and guided photothermal therapy of cancer [14]. Moreover, gelatin-coated magnetite/graphene quantum dot hybrid microspheres ( $\left.\mathrm{Fe}_{3} \mathrm{O}_{4} / \mathrm{GQDs} @ \mathrm{GM}\right)$ were advantageous as they were proved to be a biodegradable and site-specific delivery agent eliciting a strong anticancer activity [15].

Therefore, in this research, we synthesized CoNiFe and CoNiZn ternary metallic alloy nanoparticles (NPs) via polyol method and characterized from biological (in vitro tests) as well as magnetic viewpoints (through a VSM analyzer) [16]. We used the polyol method for synthesizing ternary metallic alloy CoNiFe and CoNiZn NPs [17] because it is a significant technique for preparing well-defined NPs with controlled shape and size by managing the precipitation kinetics [18]. Polyol solvents used in the synthesis of these NPs possess a high dielectric constant. Furthermore, it is known that ternary metallic alloy CoNiFe and CoNiZn NPs can elicit synergistic effects due to hybrid characteristics, such as photocatalytic properties and super-magnetism [19].

To the best of our knowledge, there are no data in the literature regarding the cytotoxicity of CoNiFe and CoNiZn NPs in cancer cells. Few works have been conducted to explore the advantages and consequences of $\mathrm{CoNiFe}$ and $\mathrm{CoNiZn}$ nanoparticles on normal and cancer cell lines for potential use in hyperthermia and electrocatalysis [20]. In fact, CoNiFe and CoNiZn NPs are involved in efficient, targeted killing of cancer cells and theranostics via induction of self-controlled hyperthermia using non-invasive techniques [20]. These ternary metallic alloys are potential thermoseeds, the surface of which can be modified to prevent dissolution, early phagocytosis, and toxicity, as well as to improve the intensity of fluorescent emitted signal and the affinity for target-specific tumor genomic sites with great flexibility [21].

Ternary metallic alloys are also highly effective in killing the cancerous as well as bacterial cells via utilizing their cytotoxic effects. In this regard, biogenically synthesized ternary nanoformulation proved to be of greater potential to inhibit cancer cells better than 
raw plant ingredients or binary AgNPs. The beneficial effects of growth inhibition can be contributed towards the enhanced stabilization and targeted action [22,23].

Ternary metallic alloys nanocomposite consisting of titanate nanotube (TNT) $/ \mathrm{CuFe}_{2} \mathrm{O}_{4} / \mathrm{Zn}$ Fe MMO were investigated for their treatment efficacy and cytotoxicity potential. It was concluded that these ternary alloys resulted in increased cellular uptake and followed a receptorindependent delivery mechanism for entrance. Moreover, the intracellular distribution of the tested nanocomposite and the potential toxicity of the tested ternary nanocomposite was dose- and time-dependent, reflecting increased cellular uptake. All these features of the TNT $/ \mathrm{CuFe}_{2} \mathrm{O}_{4} / \mathrm{Zn}$-Fe were basically proposed to induce cytotoxicity against cancer cells in prostate cancer [22].

As a useful model for in vitro cancer researches, MCF-7 cells have been considered as the first hormone-responding breast cancer cell line and have been widely studied because they retained numerous ideal characteristics particular to the mammary epithelium, including the processing of estrogen, in the form of estradiol, by means of estrogen receptors located in the cell cytoplasm [24]. On the other hand, the human umbilical vein endothelial cells (HUVECs) are commonly used for pharmacological and physiological studies (e.g., angiogenesis, fibrinolysis, macromolecule transport, and blood coagulation). Furthermore, HUVECs were previously used to examine the therapeutic efficacy of modified cationic nanocarriers [25], silicon microparticles [26], and magnetic NPs [27]. Therefore, MCF7 and HUVEC cells are useful in vitro models for cytotoxicity assessments. The current work investigates the potential in vitro toxicity of CoNiFe and CoNiZn NPs on different cell types.

\section{Materials and Methods}

\subsection{Materials}

All the chemicals used for NP synthesis, i.e., $\mathrm{NiCl}_{2} \cdot 6 \mathrm{H}_{2} \mathrm{O}, \mathrm{Co}\left(\mathrm{CH}_{3} \mathrm{COO}\right)_{2} \cdot 4 \mathrm{H}_{2} \mathrm{O}$, $\mathrm{Zn}\left(\mathrm{CH}_{3} \mathrm{COO}\right)_{2} \cdot 4 \mathrm{H}_{2} \mathrm{O}, \mathrm{FeCl}_{2} \cdot 4 \mathrm{H}_{2} \mathrm{O}$, and propylene glycol (PG), were of high purity analytical grade purchased from Merck and used as the received without further purification.

3-(4,5-dimethylthiazol-2-yl)-2,5-diphenyltetrazolium bromide (MTT), and trypsin were provided by Sigma-Aldrich (Taufkirchen, Germany). Culture mediums, Dulbecco's modified Eagle's medium (DMEM) was procured from Gibco (Rockville, MD, USA), and $0.4 \%$ Trypan blue solution was obtained from Gibco (Paisley, UK). Fetal bovine serum (FBS) was purchased from Biochrome (Berlin, Germany). Streptomycin, penicillin, and dimethyl sulfoxide (DMSO) were obtained from Sigma-Aldrich (Steinheim am Albuch, Germany). The LDH assay kit was purchased from Kalazist (KLDH96, Tehran, Iran).

\subsection{Preparation of NPS}

The polyol method was used in a typical synthesis of CoNiFe NPs [28]. Specifically, $3 \mathrm{mmol}(0.713 \mathrm{~g}) \mathrm{NiCl}_{2} \cdot 6 \mathrm{H}_{2} \mathrm{O}, 4 \mathrm{mmol}(0.795 \mathrm{~g}) \mathrm{FeCl}_{2} \cdot 4 \mathrm{H}_{2} \mathrm{O}$, and $3 \mathrm{mmol}(0.747 \mathrm{~g})$ $\mathrm{Co}\left(\mathrm{CH}_{3} \mathrm{COO}\right)_{2} \cdot 4 \mathrm{H}_{2} \mathrm{O}$ were homogeneously mixed and ground using mortar and pestle. Then, $60 \mathrm{~mL}$ of propylene glycol was heated to the boiling point $\left(170^{\circ} \mathrm{C}\right)$, and the mixed precursors were added to this hot solvent. After about $5 \mathrm{~s}, 3.5 \mathrm{~g} \mathrm{NaOH}$ pellets were also added under vigorous stirring. The color of the solution darkened and eventually turned black. In this time, the heater was turned off, and the solution was then centrifuged, washed several times with distilled water, and finally dried in an oven. Under identical conditions, CoNiZn NPs were synthesized by using $\mathrm{Zn}\left(\mathrm{CH}_{3} \mathrm{COO}\right)_{2} \cdot 4 \mathrm{H}_{2} \mathrm{O}$.

\subsection{Characterization}

X-ray diffraction measurements were performed on the annealed $\left(200{ }^{\circ} \mathrm{C}\right) \mathrm{sam}$ ples with a Rigaku D-max C III X-ray diffractometer using Ni-filtered Cu Ka1 radiation $(\lambda \approx 1.5418 \AA$ ). Microscopic morphology of products was visualized by a LEO $1455 \mathrm{VP}$ scanning electron microscope (SEM). The magnetic measurement was carried out on a vibrating sample magnetometer (VSM) (Magnetic DaneshPajoh, I. R. Iran). The results of 
the reflection loss were recorded by a vector network analyzer (VNA Agilent Technologies Inc.) in the frequency range of 8 to $12.5 \mathrm{GHz}$.

\subsection{Cell Culture and Exposure of NPs}

HUVEC cells were procured from the National Cell Bank of Iran (Tehran, Iran) and selected as a widely used in vitro model of normal cells. Michigan Cancer Foundation-7 (MCF-7) human breast cancer cells, obtained from the same cell repository, were chosen as an appropriate in vitro model of solid tumors. Cells were cultivated in DMEM culture medium supplemented with 10\% heat-inactivated FBS, $100 \mathrm{U} / \mathrm{mL}$ penicillin-streptomycin, and preserved under standard conditions $\left(5 \% \mathrm{CO}_{2}, 37^{\circ} \mathrm{C}\right)$. At $80 \%$ confluence, cells were detached from culture flasks using Trypsin $0.25 \%$ and sub-cultured into $75 \mathrm{~cm}^{2}$ flasks, 96-well microplates for further assessments. CoNiFe, and CoNiZn NPs were suspended in culture medium and diluted to appropriate concentrations $(0,12.5,25,50,100,200$, and $400 \mu \mathrm{g} / \mathrm{mL}$ ).

\subsection{Cytotoxicity Evaluation and Morphological Observation}

An MTT assay was used to investigate the cell-killing effect of the synthesized magnetic NPs as described before [29]. Briefly, $5 \times 10^{3}$ cells/well were seeded in 96-well microplates and exposed to increasing concentrations $(0,12.5,25,50,100,200$, and $400 \mu \mathrm{g} / \mathrm{mL})$ of CoNiFe and CoNiZn NPs for 24 and $48 \mathrm{~h}$. At the end of the exposure, the culture medium was carefully discarded, and $200 \mu \mathrm{L}$ of MTT solution $(0.5 \mathrm{mg} / \mathrm{mL})$ was added to each microwell and kept in an incubator for $3 \mathrm{~h}$ at $37^{\circ} \mathrm{C}$. Then, the supernatant was replaced with $200 \mu \mathrm{L}$ of DMSO to allow complete dissolving of formazan crystals. The plates were kept on a shaker for $15 \mathrm{~min}$ at $25^{\circ} \mathrm{C}$ and analyzed using a SpectraMax multi-plate reader (Molecular Devices, Sunnyvale, CA, USA) at $570 \mathrm{~nm}$. Results were expressed as percentages of viable cells calculated by dividing the optical density (OD) measured for treated cells by the OD measured for untreated cells $\times 100$. The half-maximal inhibitory concentration $\left(\mathrm{IC}_{50}\right)$ was calculated using GraphPad Prism 7.0Aa (San Diego, CA, USA) software.

The morphology of MCF7 and HUVEC cells were monitored after exposure to $100 \mu \mathrm{g} / \mathrm{mL}$ of CoNiFe and CoNiZn NPs for $48 \mathrm{~h}$ using an inverted phase-contrast microscope (IX70, Olympus, Tokyo, Japan).

\subsection{Lactate Dehydrogenase Leakage Assay}

The release of cytoplasmic lactate dehydrogenase (LDH) into the culture medium was determined using a colorimetric LDH-based in vitro toxicity assay kit, according to the manufacturer's protocol. HUVEC and MCF-7 cells were treated with increasing concentrations $(0,12.5,25,50,100,200$, and $400 \mu \mathrm{g} / \mathrm{mL})$ of CoNiFe and CoNiZn NPs for 24 and $48 \mathrm{~h}$. After exposure, $100 \mu \mathrm{L}$ samples from the centrifuged culture media were added to each well of a 96-well microplate for evaluation. The LDH leakage (\% of positive control) was expressed as the percentage of $\left(\mathrm{OD}_{\text {test }}-\mathrm{OD}_{\text {blank }}\right) /\left(\mathrm{OD}_{\text {positive }}-\mathrm{OD}_{\text {blank }}\right)$, where $\mathrm{OD}_{\text {test }}$ shows the OD of control or NP exposed cells, OD positive is the OD of the control positive cells, and $\mathrm{OD}_{\text {blank }}$ is the OD of the wells without cells. The ODs were read at $540 \mathrm{~nm}$ against $592 \mathrm{~nm}$ as background using a SpectraMax multi-plate reader (Molecular Devices, Sunnyvale, CA, USA).

\subsection{Statistical Analysis}

All statistical analyses were performed using SPSS version 22.0 software (SPSS Inc, Chicago, IL, USA). Results were expressed as mean \pm standard deviation (SD). The significance of difference was examined using ANOVA and Bonferroni's tests; $p<0.05$ was considered significant. 


\section{Results and Discussion}

\subsection{Characterization of NPS}

The XRD pattern of CoNiFe showed (111), (200), and (220) reflections (Figure 1a), which matched with the standard JCPDS data for FeNi with the lattice parameter $\mathrm{a}=\mathrm{b}=\mathrm{c}=3.5450 \AA$ (No: 00-038-0419). The crystal structure was also found to be face-cubic centered (FCC) with the main peaks (111), (200), and (220) revealed by XRD pattern. The crystal structure of the CoNiZn sample was found to be FCC as well (JCPDS 89-4307) with the main peaks (111), (200), and (220), as shown in Figure $1 \mathrm{~b}$. The crystalline sizes were calculated to be around $12.0 \mathrm{~nm}$ using the DebyeScherrer formula based on the full width at half maximum (FWHM) of the main diffraction peak (111).
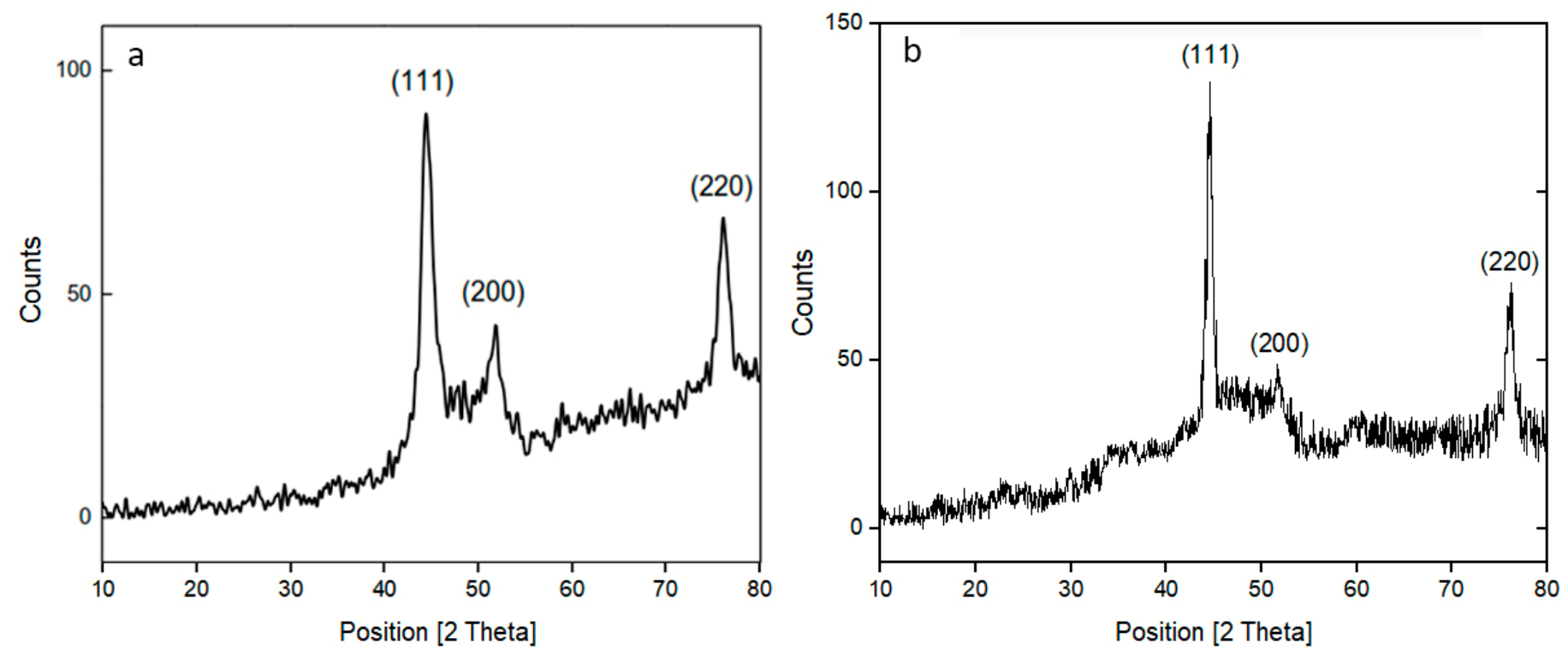

Figure 1. XRD patterns of the synthesized (a) CoNiFe, and (b) CoNiZn samples.

The SEM images of the prepared ternary alloys CoNiFe and CoNiZn are shown in Figure 2. The related size distribution diagrams were also prepared by the Digimizer software. Some sub-micrometric spheres can be seen in both figures; such spheres are composed of assemblies of smaller nanoparticles aggregated due to different reasons, such as the magnetic interaction between the magnetic nanoparticles [13,22]. According to Figure $2 \mathrm{~b}$, the average particle size of the CoNiFe sample was $8 \mathrm{~nm}$, while it was about $17 \mathrm{~nm}$ in Figure $2 \mathrm{~d}$ for CoNiZn. So, the average particle size, as well as the diameter of the spheres, of CoNiFe NPs was smaller than of CoNiZn.

A vibrating sample magnetometer (VSM) was used to measure the magnetic properties of the prepared samples. In brief, the synthesized sample was placed in an applied positive magnetic field $\mathrm{H}$. Then, the sample was vibrated vertically, and the induced magnetic field was created so that the induced current was proportional to the magnetization of the sample. After the magnetization of the sampled saturated up to $\mathrm{M}_{\mathrm{s}}$, the magnetic field was decreased to zero, but a little magnetization remained in the ferromagnetic sample. So, a negative magnetic field was applied to remove the remanent magnetization, which is called coercive field $\mathrm{H}_{\mathrm{c}}$. By repeating this cycle, the $\mathrm{M}-\mathrm{H}$ curve was obtained with a hysteresis loop.

The hysteresis loop observed in Figure 3 indicates the soft ferromagnetic behavior for the prepared samples. CoNiFe sample showed the higher magnetic saturation $\mathrm{M}_{\mathrm{s}}=94 \mathrm{emu} / \mathrm{g}$ in comparison with CoNiZn $\left(\mathrm{M}_{\mathrm{s}}=46.6 \mathrm{emu} / \mathrm{g}\right)$, while it had the lower coercive field $\mathrm{H}_{\mathrm{c}}$ value of about $68.7 \mathrm{Oe}$. This can be due to the smaller particle grains of the CoNiFe sample. The magnetic element Fe caused a higher magnetization of $\mathrm{CoNiFe}$ compared with CoNiZn. On the other hand, the non-magnetic element $\mathrm{Zn}$ segregated 
between Fe and Co elements and led to a reduced magnetostatic interaction as well as a higher Hc value compared to that of CoNiFe.
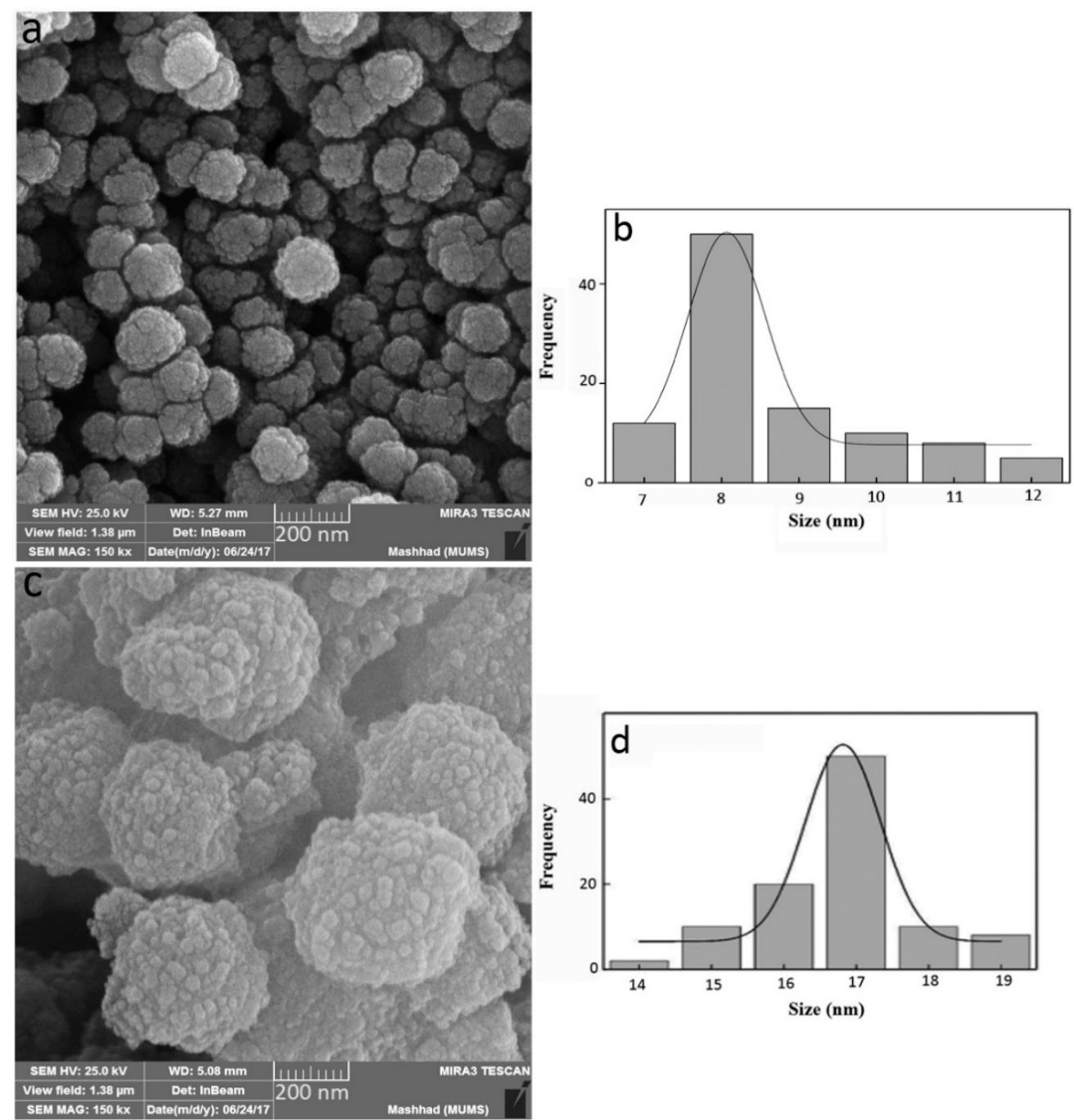

Figure 2. (a,b) SEM images and size distribution of the synthesized CoNiFe sample, respectively; (c,d) SEM images and size distribution of the synthesized CoNiZn samples, respectively.

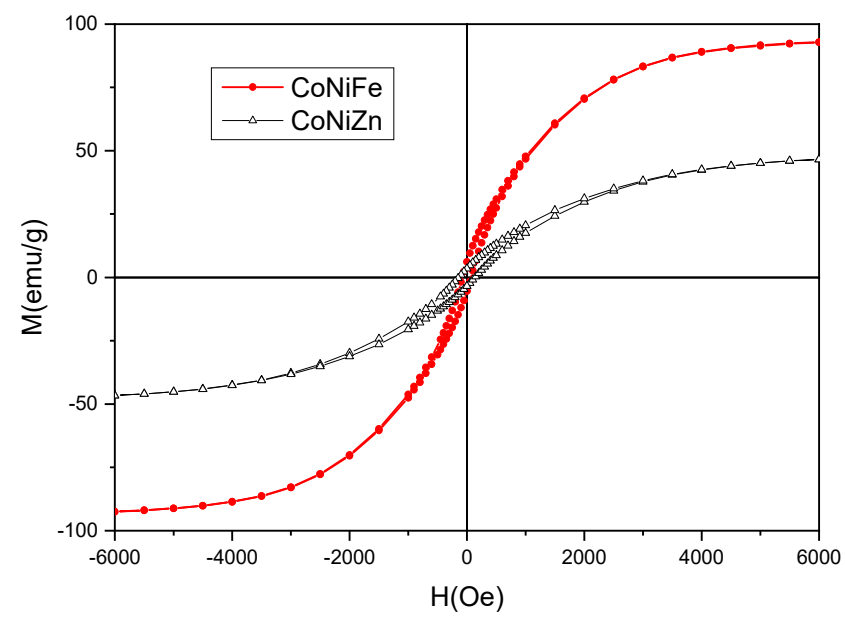

Figure 3. The magnetic hysteresis loops of the prepared samples. 


\subsection{Determination of Cell Sensitivity to NPs}

We assessed MTT reduction and LDH leakage as determinants of mitochondrial function and membrane damage, respectively. Compared with untreated cells, MTT results demonstrated a time- and concentration-dependent toxicity and a significant reduction in survival of MCF7 and HUVEC cells after exposure to either CoNiZn (Figure 4) or CoNiFe (Figure 5) NPs $(p<0.05)$. The percentages of viable HUVEC cells after $48 \mathrm{~h}$ exposure at concentrations $12.5,25,50,100,200$, and $400 \mu \mathrm{g} / \mathrm{mL}$ of CoNiZn NPs were $88 \%, 79 \%$, $76 \%, 71 \%, 44 \%$, and $24 \%$, while the percentage of viable MCF7 cells treated with the same concentrations of CoNiZn NPs within the given time period was $80 \%, 71 \%, 47 \%, 40 \%$, $38 \%$, and $17 \%$ (Figure 4 ). Similarly, the percentages of viable MCF7 cells following $48 \mathrm{~h}$ treatment with concentrations $12.5,25,50,100,200$, and $400 \mu \mathrm{g} / \mathrm{mL}$ of CoNiFe NPs were $75,71,65,48,37$, and $14 \%$, while these percentages were $88 \%, 79 \%, 70,52 \%, 35 \%$, and $19 \%$ for HUVEC cells (Figure 5). IC 50 values for exposure of cells to CoNiZn NPs were 211.8 and $163.5 \mu \mathrm{g} / \mathrm{mL}$ (after 24 and $48 \mathrm{~h}$ for HUVEC cells), and 89.24 and $64.06 \mu \mathrm{g} / \mathrm{mL}$ (after 24 and $48 \mathrm{~h}$ for MCF7 cells), respectively. Furthermore, the $\mathrm{IC}_{50}$ concentrations of CoNiFe NPs were 228.2 and $106.5 \mu \mathrm{g} / \mathrm{mL}$ (after 24 and $48 \mathrm{~h}$ for HUVEC cells), and 124.3 and $82.71 \mu \mathrm{g} / \mathrm{mL}$ (after 24 and $48 \mathrm{~h}$ for MCF7 cells). We observed that MCF7 cells were more susceptible to the prepared NPs, indicated by lower $\mathrm{IC}_{50}$ s. It can be concluded that CoNiZn and $\mathrm{CoNiFe}$ NPs induced higher toxicity on cells derived from the human breast tissue and exerted less toxicity on normal human cells $\left(\mathrm{IC}_{50}>100 \mu \mathrm{g} / \mathrm{mL}\right)$.

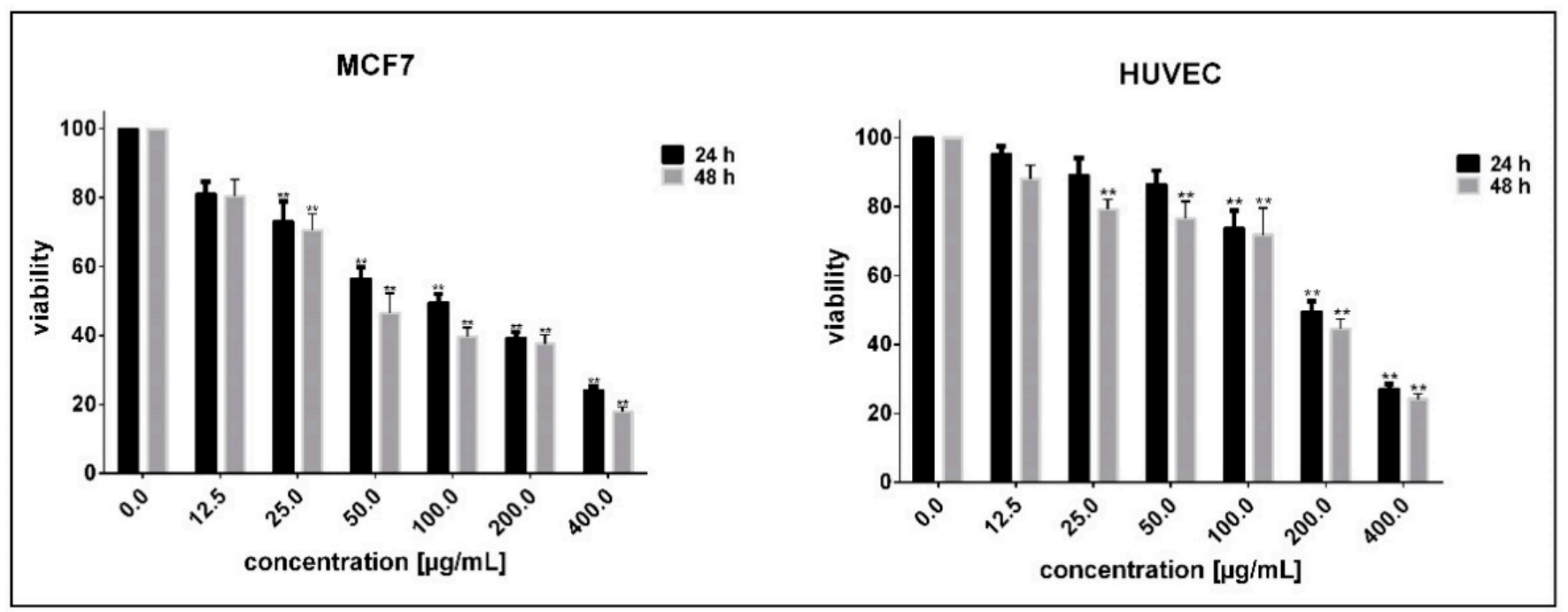

Figure 4. Time- and concentration-dependent toxicity of CoNiZn NPs on Michigan Cancer Foundation-7 (MCF7) and human umbilical vascular endothelial cells (HUVEC) using MTT colorimetric assay following 24 and $48 \mathrm{~h}$ incubation. Data are expressed as mean $\pm \mathrm{SD}$ from one representative of three independent experiments. $\quad{ }^{* *} p<0.05$ compared with untreated cells).

LDH enzyme release assay is widely used in in vitro toxicological studies. Therefore, we measured LDH leakage in MCF7 and HUVEC cells exposed to 12.5, 25, 50, 100, 200, and $400 \mu \mathrm{g} / \mathrm{mL}$ of the synthesized NPs for $48 \mathrm{~h}$. Compared with untreated cells, exposure of HUVEC cells with $12.5 \mu \mathrm{g} / \mathrm{mL}$ of CoNiZn and CoNiFe NPs did not enhance LDH leakage $(p>0.05)$. However, with increasing NP concentration, significant LDH leakage was observed in both cell lines as compared with untreated cells $(p<0.05)$ (Figure 6). 


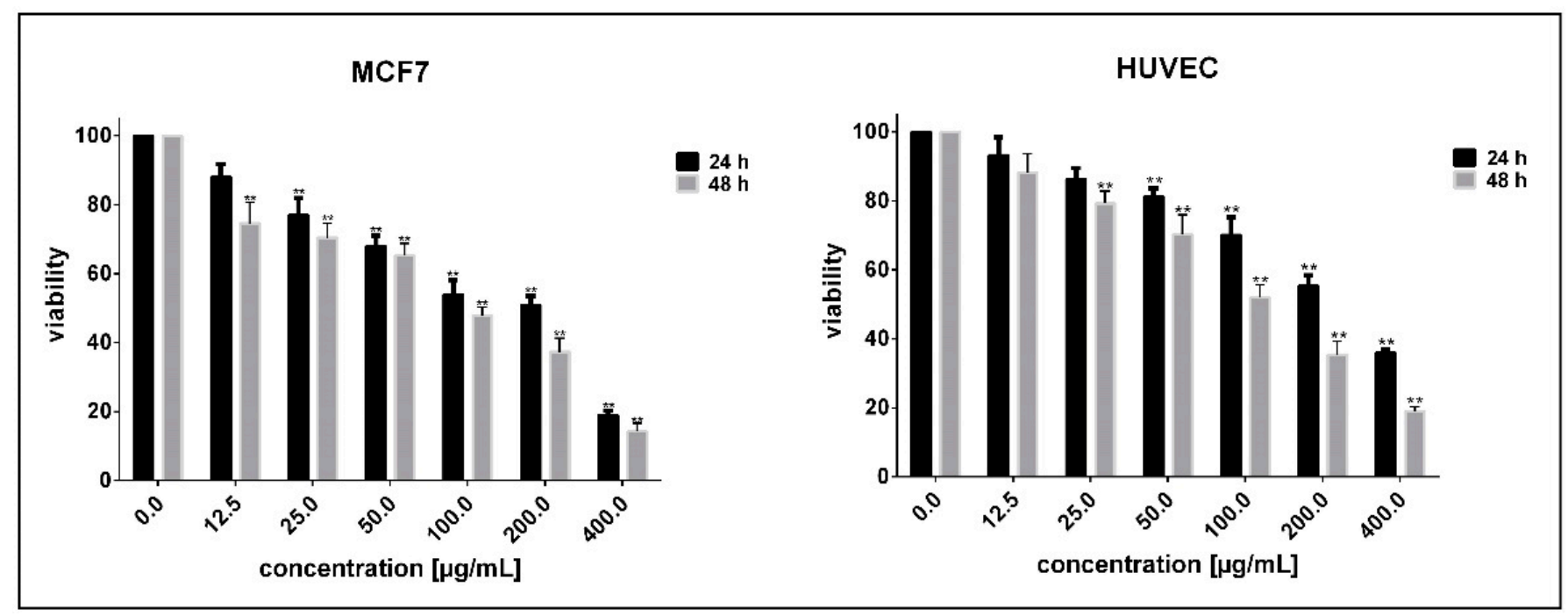

Figure 5. Time- and concentration-dependent toxicity of CoNiFe NPs on Michigan Cancer Foundation-7 (MCF7) and human umbilical vascular endothelial cells (HUVECs) using MTT colorimetric assay following 24 and $48 \mathrm{~h}$ incubation. Data are expressed as mean $\pm \mathrm{SD}$ from one representative of three independent experiments. $(* * p<0.05$ compared with untreated cells).

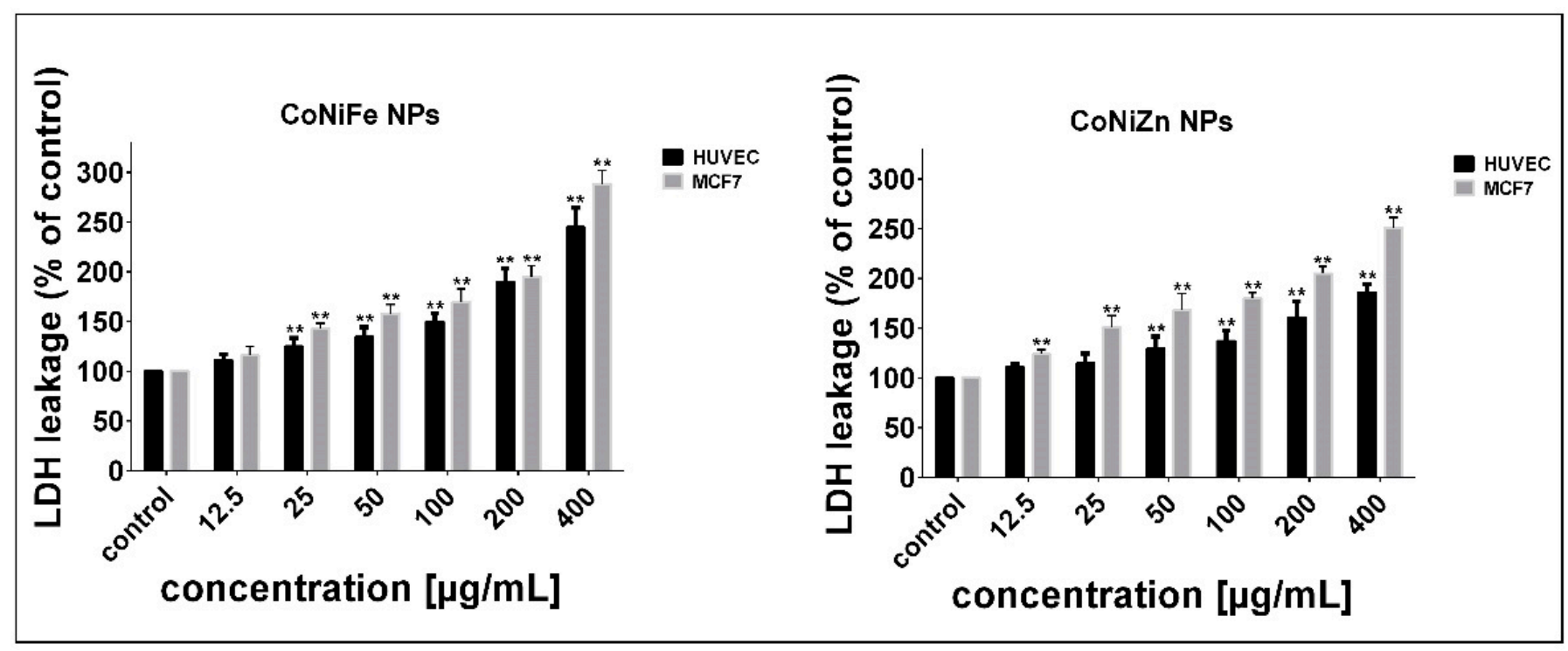

Figure 6. LDH leakage caused by CoNiZn and CoNiFe NPs following $48 \mathrm{~h}$ of exposure. Data are expressed as mean $\pm \mathrm{SD}$ from one representative of three independent experiments (** $p<0.05$ compared with untreated cells).

\subsection{Morphological Changes}

Treatment of HUVEC and MCF7 cells with concentrations less than $25 \mu \mathrm{g} / \mathrm{mL}$ of CoNiZn and CoNiFe NPs did not induce noticeable morphological alterations after $48 \mathrm{~h}$. Exposure of HUVEC cells to $100 \mu \mathrm{g} / \mathrm{mL}$ of the prepared NPs for $48 \mathrm{~h}$ moderately decreased the cell viability without causing evident morphological changes. At the same time, the number of alive MCF7 cells treated with CoNiZn NPs was reduced, cells were shrunk, and apoptotic bodies were formed. In comparison with CoNiZn-treated MCF7 cells, CoNiFe-treated MCF7 cells were less affected. However, cell shrinkage, detachment of cells from culture plate, and formation of vacuolated cells were evident hallmarks of MCF7 cells treated with CoNiFe NPs at the given concentration (Figure 7).

In the current study, CoNiFe and CoNiZn alloy NPs were synthesized by the polyol method and then characterized by XRD, SEM, and VSM analyses. Generally, because of the excellent magnetic and physical properties, such as superior corrosion resistance, low co- 
ercivity, and high resistivity, the ternary alloys of CoNiFe are interesting materials for many high-added-value applications [30]; for example, Koay et al. used nanocrystalline CoNiFe to protect stainless steel from a sodium chloride environment [31]. Recently, various types of superparamagnetic and ferromagnetic nanoparticles heated with alternating magnetic fields have been used in novel cancer therapies [32]. It was reported that the power loss in single-domain magnetic nanoparticles with a specific size range was significantly greater than that in multi-domain nanoparticles [33]. The CoNiFe NPs synthesized in this work, with the average crystalline size of $12.1 \mathrm{~nm}$, showed the magnetic saturation $\mathrm{M}_{\mathrm{s}}=94 \mathrm{emu} / \mathrm{g}$. This sample can be fully saturated under the applied field because of its low coercive field (68.7 Oe). However, the spherical-shaped particles and the internal coupling interactions between the magnetic moments may influence the response to the applied alternating magnetic field [34]. Our in vitro cytotoxicity measurements revealed that CoNiZn and CoNiFe NPs induced time- and concentration-dependent toxicity and enhanced the LDH leakage in cancerous (MCF7) and non-cancerous (HUVEC) cell lines. However, unlike cancer cells, normal human cells were less affected during exposure to either CoNiZn or CoNiFe NPs.

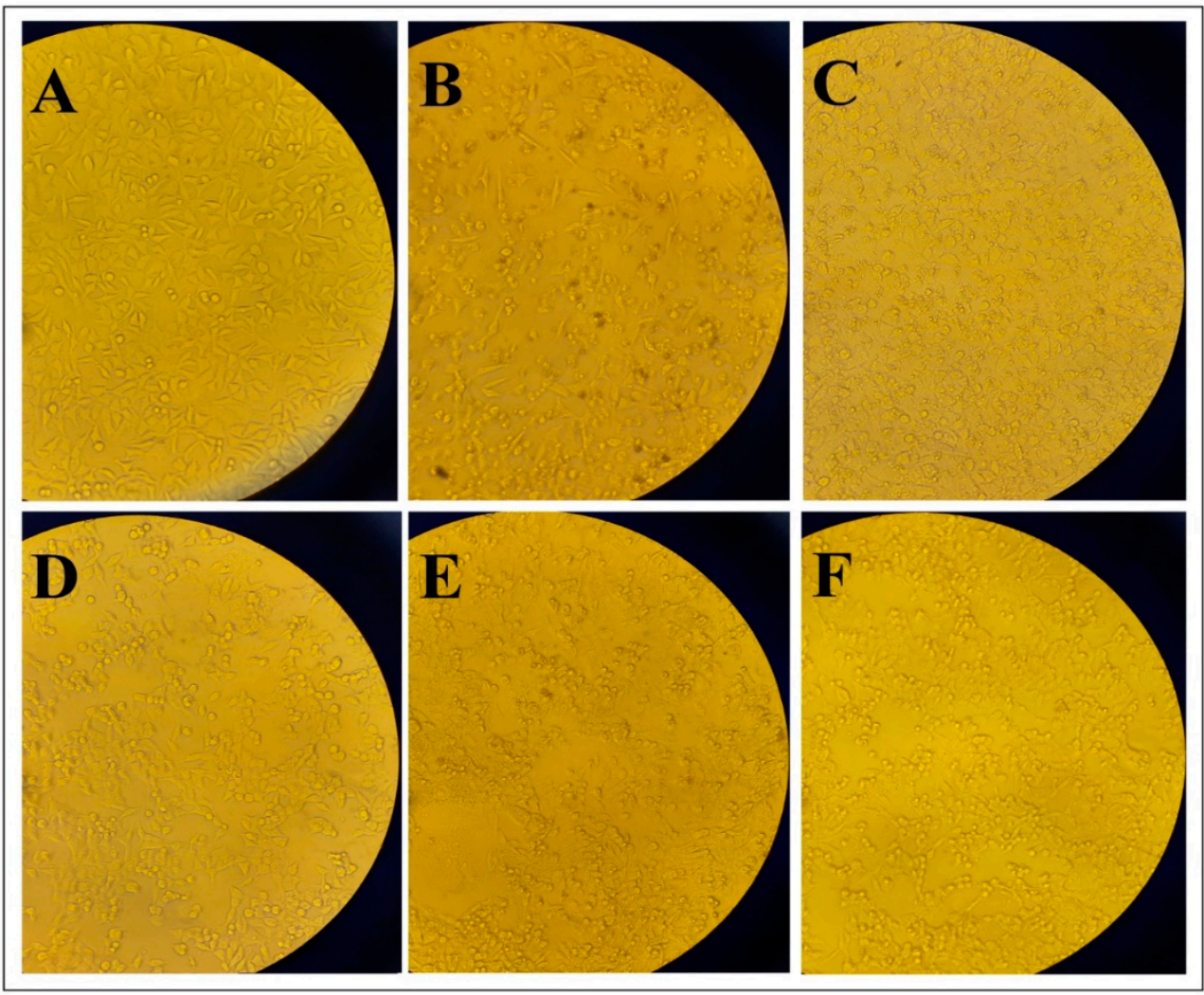

Figure 7. Optical microscopy images of cells treated with NPs for $48 \mathrm{~h}$. (A) untreated Michigan Cancer Foundation-7 (MCF7) cells; (B) MCF7 cells treated with $100 \mu \mathrm{g} / \mathrm{mL}$ of CoNiZn NPs; (C) MCF7 cells treated with $100 \mu \mathrm{g} / \mathrm{mL}$ of CoNiFe NPs; (D) untreated human umbilical vascular endothelial cells (HUVECs); (E) HUVEC cells treated with $100 \mu \mathrm{g} / \mathrm{mL}$ of CoNiZn NPs; (F) HUVEC cells treated with $100 \mu \mathrm{g} / \mathrm{mL}$ of CoNiFe NPs.

Nanotechnology has emerged as a novel field with potentially high research and clinical impact $[35,36]$. In this respect, metallic alloy NPs have been introduced as a promising strategy to enhance therapeutic efficacy against cancer cells through enhancing the reuptake, increasing reactive oxygen species production in cells, and, therefore, causing mitochondrial damage [37]. It has also been established that $\mathrm{Au}-\mathrm{Ag}$ alloy NPs prepared via green synthesis could be applied as beneficial growth inhibitors for several biomedical applications [38]. Green synthesis of hollow CoPt alloy NPs has brought new insights in utilizing biocompatible NPs for theranostic applications [39]. Patskovsky et al. reported 
that single $\mathrm{Au}, \mathrm{Ag}$, and $\mathrm{Au} / \mathrm{Ag}$ alloy NPs have considerable advantages for NP imaging in the cellular environment, a highly diffusing medium [40]. In a similar study, Karthika and coworkers studied the cytostatic and antimicrobial effects of newly prepared $\mathrm{Ag}, \mathrm{Au}$, and $\mathrm{Ag} / \mathrm{Au}$ alloy NPs. The biosynthesized NPs had spherical shape, demonstrated good catalytic activity and exerted desirable cytotoxic effects against Hela cervical cancer cells. In their study, the $\mathrm{IC}_{50}$ of $\mathrm{Ag} / \mathrm{Au}$ alloy NPs were found to be $24.83 \mu \mathrm{M}$, being the most active at concentration of $100 \mu \mathrm{M}$ as cell viability reaches $47.50 \%$ [41]. These findings highlight the benefits of preparing metallic alloy NPs as cheap sources to establish new and safe anti-proliferative agents.

Our in vitro findings of CoNiZn and CoNiFe NPs indicated that the CoNiZn NPs exerted more desirable cytotoxicity against breast cancer cells, confirmed by lower $\mathrm{IC}_{50} \mathrm{~s}$. On the other hand, NPs exhibiting magnetic properties are highly appealing for cancer treatment. Magnetic NPs possess unique physicochemical properties, which attract many researchers to perform in vitro investigations about their beneficial applications in medicine [42]. In this regard, cancer therapy and hyperthermia treatment are two of the most promising applications of magnetic NPs that have recently shown promising outcomes [43]. Furthermore, these NPs have shown great advantages in cancer nanotheranostics, as they can play an important role as MRI probes [44]. Still, the synthesized magnetic NPs must be safe when applied to normal human tissues. Based on MTT results, we found that exposure of normal human cells to $12.5 \mu \mathrm{g} / \mathrm{mL}$ of CoNiZn and CoNiFe NPs did not induce any significant cytotoxicity. Furthermore, no evident morphological alteration and membrane damage was noticed when HUVEC cells were treated with the given dose of the NPs for $48 \mathrm{~h}$. Therefore, we believe that it would be appropriate to consider $12.5 \mu \mathrm{g} / \mathrm{mL}$ as the safe dose for both NPs for further assessments and future applications.

Peymani-Motlagh et al. examined the cytotoxic effects of $\mathrm{Co}_{0.5} \mathrm{Ni}_{0.5} \mathrm{Pr}_{0.1} \mathrm{Fe}_{1.9} \mathrm{O}_{4}$ magnetic NPs on the Hela cell line. They found that these NPs did not exert cytotoxic any significant effects in human lung cancer cells at concentrations of up to $500 \mu \mathrm{g} / \mathrm{mL}$ after $24 \mathrm{~h}$ exposure [45]. In contrast with these findings, we observed potent cell-killing effects on MCF7 cells after $24 \mathrm{~h}$ and $48 \mathrm{~h}$ exposure to prepared NPs at concentrations higher than $12.5 \mu \mathrm{g} / \mathrm{mL}$. The observed difference between our findings and Peymani-Motlagh et al.'s results might be due to the composition of the studied NPs (presence of $\mathrm{Yb}^{3+}$. and $\mathrm{Pr}^{3+}$-substituted cobalt-nickel ferrite NPs in the latter) and the type of the studied cell lines. Still, our NPs had negligible or non-cytotoxic effects at $12.5 \mu \mathrm{g} / \mathrm{mL}$. By performing both MTT and trypan blue exclusion assays, Martínez-Rodríguez and coworkers assessed the in vitro toxicity of zinc and nickel ferrite NPs in human erythrocytes and peripheral blood mononuclear (PBM) cells. After treatment with $50 \mathrm{or} 200 \mathrm{\mu g} / \mathrm{mL}$ of ferrite NPs for $24 \mathrm{~h}$, the number of alive PBM cells was not decreased, and, thus, nickel, zinc, nickel-zinc ferrite magnetic NPs did not significantly induce cell death in normal human cells [46].

\section{Conclusions}

Two famous ternary alloys CoNiFe and CoNiZn NPs were prepared by the polyol chemical method. SEM investigations revealed spherical-shaped grains for both samples; however, the grains of the CoNiZn were seen to be more aggregated with a larger average diameter. The obtained magnetic loops by the VSM characterization of samples demonstrated the $M_{s}=94 \mathrm{emu} / \mathrm{g}$ and $\mathrm{H}_{\mathrm{c}}=68.7 \mathrm{Oe}$ for the CoNiFe sample, and $\mathrm{M}_{\mathrm{s}}=46.6 \mathrm{emu} / \mathrm{g}$ and $\mathrm{H}_{\mathrm{C}}=68.7 \mathrm{Oe}$ for the CoNiZn. The magnetic element Fe causes a higher magnetization of CoNiFe compared with CoNiZn. On the other hand, the non-magnetic element $\mathrm{Zn}$ segregates between $\mathrm{Fe}$ and $\mathrm{Co}$ elements and leads to a reduced magnetostatic interaction as well as a higher $\mathrm{H}_{\mathrm{c}}$ value rather than that of $\mathrm{CoNiFe}$, and this is the differences between CoNiZn and CoNiFe NPs.

Many studies have been conducted to ensure the efficiency, safety, and basic and clinical implications of metallic alloy NPs. Our in vitro findings suggested that the CoNiZn and CoNiFe treatment with the dose of $12.5 \mu \mathrm{g} / \mathrm{mL}$ was safe and did not affect the survival of normal human cells. These early biological results motivate further research on 
the prepared NPs, in the effort to build high-performance theranostic nanoplatforms for simultaneous cancer imaging and therapy without affecting normal human cells.

Author Contributions: Conceptualization, A.R.; investigation, S.A.-A., M.A.-K., S.S., R.A.; writing—original draft preparation, S.S., S.A.-A., M.A.-K., R.A.; writing—review and editing, S.S., A.R., F.B.; resource, S.A.-A., M.A.-K., S.S., A.R., R.A., F.B.; supervision, A.R. All authors have read and agreed to the published version of the manuscript.

Funding: This study received funding from Zahedan University of Medical Sciences (Project. 10267).

Institutional Review Board Statement: The in vitro part of the study protocol was approved by Zahedan University of Medical Sciences (Ethical code: IR.ZAUMS.REC.1399.517).

Informed Consent Statement: Not applicable.

Data Availability Statement: Data included in the paper.

Conflicts of Interest: The authors declare no conflict of interest.

\section{References}

1. Madamsetty, V.S.; Mukherjee, A.; Mukherjee, S. Recent Trends of the Bio-Inspired Nanoparticles in Cancer Theranostics. Front. Pharmacol. 2019, 10. [CrossRef]

2. Chen, G.; Qiu, H.; Prasad, P.N.; Chen, X. Upconversion nanoparticles: Design, nanochemistry, and applications in theranostics. Chem. Rev. 2014, 114, 5161-5214. [CrossRef]

3. Gobbo, O.L.; Sjaastad, K.; Radomski, M.W.; Volkov, Y.; Prina-Mello, A. Magnetic nanoparticles in cancer theranostics. Theranostics 2015, 5, 1249. [CrossRef]

4. Fernandes, N.; Rodrigues, C.F.; Moreira, A.F.; Correia, I.J. Overview of the application of inorganic nanomaterials in cancer photothermal therapy. Biomater. Sci. 2020, 8, 2990-3020. [CrossRef]

5. Qin, X.; Kim, D.; Piao, Y. Metal-organic frameworks-derived novel nanostructured electrocatalysts for oxygen evolution reaction. Carbon Energy 2021, 3, 66-100. [CrossRef]

6. Lu, L. Nanoporous noble metal-based alloys: A review on synthesis and applications to electrocatalysis and electrochemical sensing. Microchim. Acta 2019, 186, 1-21. [CrossRef]

7. Taylor, U.; Tiedemann, D.; Rehbock, C.; Kues, W.A.; Barcikowski, S.; Rath, D. Influence of gold, silver and gold-silver alloy nanoparticles on germ cell function and embryo development. Beilstein J. Nanotechnol. 2015, 6, 651-664. [CrossRef]

8. Tiedemann, D.; Taylor, U.; Rehbock, C.; Jakobi, J.; Klein, S.; Kues, W.A.; Barcikowski, S.; Rath, D. Reprotoxicity of gold, silver, and gold-silver alloy nanoparticles on mammalian gametes. Analyst 2014, 139, 931-942. [CrossRef]

9. $\quad$ Elegbede, J.A.; Lateef, A.; Azeez, M.A.; Asafa, T.B.; Yekeen, T.A.; Oladipo, I.C.; Hakeem, A.S.; Beukes, L.S.; Gueguim-Kana, E.B. Silver-gold alloy nanoparticles biofabricated by fungal xylanases exhibited potent biomedical and catalytic activities. Biotechnol. Prog. 2019, 35, e2829. [CrossRef]

10. Akin, Y.; Obaidat, I.; Issa, B.; Haik, Y. Ni1-x Crx alloy for self controlled magnetic hyperthermia. Cryst. Res. Technol. J. Exp. Ind. Crystallogr. 2009, 44, 386-390. [CrossRef]

11. Magaye, R.; Zhao, J.; Bowman, L.; Ding, M. Genotoxicity and carcinogenicity of cobalt-, nickel-and copper-based nanoparticles. Exp. Ther. Med. 2012, 4, 551-561. [CrossRef] [PubMed]

12. Stergar, J.; Ban, I.; Maver, U. The Potential Biomedical Application of NiCu Magnetic Nanoparticles. Magnetochemistry 2019, 5, 66. [CrossRef]

13. Dang, W.; Li, T.; Li, B.; Ma, H.; Zhai, D.; Wang, X.; Chang, J.; Xiao, Y.; Wang, J.; Wu, C. A bifunctional scaffold with CuFeSe2 nanocrystals for tumor therapy and bone reconstruction. Biomaterials 2018, 160, 92-106. [CrossRef] [PubMed]

14. Wu, N.; Li, Y.; Zeng, M.; Gao, J.; Tang, Y.; Zeng, Z.; Zheng, Y. Design of chalcopyrite-type CuFeSe2 nanocrystals: Microstructure, magnetism, photoluminescence and sensing performances. J. Solid State Chem. 2019, 271, 292-297. [CrossRef]

15. Pooresmaeil, M.; Namazi, H. pH-sensitive ternary Fe3O4/GQDs@ G hybrid microspheres; Synthesis, characterization and drug delivery application. J. Alloys Compd. 2020, 846, 156419. [CrossRef]

16. Loh, A.; Li, X.; Taiwo, O.O.; Tariq, F.; Brandon, N.P.; Wang, P.; Xu, K.; Wang, B. Development of Ni-Fe based ternary metal hydroxides as highly efficient oxygen evolution catalysts in AEM water electrolysis for hydrogen production. Int. J. Hydrog. Energy 2020, 45, 24232-24247. [CrossRef]

17. Kube, S.A.; Xing, W.; Kalidindi, A.; Sohn, S.; Datye, A.; Amram, D.; Schuh, C.A.; Schroers, J. Combinatorial study of thermal stability in ternary nanocrystalline alloys. Acta Mater. 2020, 188, 40-48. [CrossRef]

18. Elsherif, S.A.; El Sawy, E.N.; Ghany, N.A.A. Polyol synthesized graphene/PtxNi100-x nanoparticles alloy for improved electrocatalytic oxidation of methanol in acidic and basic media. J. Electroanal. Chem. 2020, 856, 113601. [CrossRef]

19. Dippong, T.; Cadar, O.; Levei, E.A.; Deac, I.G. Microstructure, porosity and magnetic properties of Zn0. 5Co0. 5Fe2O4/SiO2 nanocomposites prepared by sol-gel method using different polyols. J. Magn. Magn. Mater. 2020, 498, 166168. [CrossRef] 
20. Salati, A.; Ramazani, A.; Kashi, M.A. Tuning hyperthermia properties of FeNiCo ternary alloy nanoparticles by morphological and magnetic characteristics. J. Magn. Magn. Mater. 2020, 498, 166172. [CrossRef]

21. Fotukian, S.M.; Barati, A.; Soleymani, M.; Alizadeh, A.M. Solvothermal synthesis of $\mathrm{CuFe}_{2} \mathrm{O}_{4}$ and $\mathrm{Fe}_{3} \mathrm{O}_{4}$ nanoparticles with high heating efficiency for magnetic hyperthermia application. J. Alloys Compd. 2020, 816, 152548. [CrossRef]

22. El-Shahawy, A.A.; Moaty, S.A.; Zaki, A.; Mohamed, N.A.; GadelHak, Y.; Mahmoud, R.; Farghali, A. Prostate Cancer Cellular Uptake of Ternary Titanate Nanotubes/CuFe2O4/Zn-Fe Mixed Metal Oxides Nanocomposite. Int. J. Nanomed. 2020, 15, 619. [CrossRef] [PubMed]

23. Yang, M.; Lu, F.; Zhou, T.; Zhao, J.; Ding, C.; Fakhri, A.; Gupta, V.K. Biosynthesis of nano bimetallic Ag/Pt alloy from Crocus sativus L. extract: Biological efficacy and catalytic activity. J. Photochem. Photobiol. B Biol. 2020, 212, 112025. [CrossRef]

24. Camarillo, I.G.; Xiao, F.; Madhivanan, S.; Salameh, T.; Nichols, M.; Reece, L.M.; Leary, J.F.; Otto, K.; Natarajan, A.; Ramesh, A. Low and high voltage electrochemotherapy for breast cancer: An in vitro model study. Electroporation Based Ther. Cancer 2014, 55-102. [CrossRef]

25. Chen, X.; Wang, X.; Wang, Y.; Yang, L.; Hu, J.; Xiao, W.; Fu, A.; Cai, L.; Li, X.; Ye, X. Improved tumor-targeting drug delivery and therapeutic efficacy by cationic liposome modified with truncated bFGF peptide. J. Control. Release 2010, 145, 17-25. [CrossRef] [PubMed]

26. Serda, R.E.; Gu, J.; Bhavane, R.C.; Liu, X.; Chiappini, C.; Decuzzi, P.; Ferrari, M. The association of silicon microparticles with endothelial cells in drug delivery to the vasculature. Biomaterials 2009, 30, 2440-2448. [CrossRef] [PubMed]

27. Zhang, L.; Xue, H.; Gao, C.; Carr, L.; Wang, J.; Chu, B.; Jiang, S. Imaging and cell targeting characteristics of magnetic nanoparticles modified by a functionalizable zwitterionic polymer with adhesive 3, 4-dihydroxyphenyl-1-alanine linkages. Biomaterials 2010, 31, 6582-6588. [CrossRef]

28. Mokarian, M.H.; Almasi-kashi, M.; Alikhanzadeh-Arani, S.; Ramazani, A. The fcc/bcc phase transition in FexNi100-x nanoparticles resolved by first-order reversal curves. J. Mater. Sci. 2017, 52, 7831-7842. [CrossRef]

29. Mashayekhi, S.; Rasoulpoor, S.; Shabani, S.; Esmaeilizadeh, N.; Serati-Nouri, H.; Sheervalilou, R.; Pilehvar-Soltanahmadi, Y. Curcumin-loaded mesoporous silica nanoparticles/nanofiber composites for supporting long-term proliferation and stemness preservation of adipose-derived stem cells. Int. J. Pharm. 2020, 587, 119656. [CrossRef] [PubMed]

30. Resali, N.A.; Hyie, K.M.; Berhan, M.; Mardziah, C. Investigation of Heat Treated Electrodeposited CoNiFe on Microstructure and Hardness. In Advanced Materials Research; Trans Tech Publications Ltd.: Stafa-Zurich, Switzerland, 2015 ; pp. 56-61.

31. Koay, M.H.; Salleh, Z.; Mardziah, C.; Mohd Masdek, N.R.N.; Resali, N.A. Corrosion Behavior of Heat Treated Nanocrystalline Co Ni Fe Coating on Stainless Steel/Koay Mei Hyie ... [et al.]. J. Mech. Eng. 2018, 5, 191-203.

32. Fatima, H.; Charinpanitkul, T.; Kim, K.-S. Fundamentals to Apply Magnetic Nanoparticles for Hyperthermia Therapy. Nanomaterials 2021, 11, 1203. [CrossRef] [PubMed]

33. Giustini, A.J.; Petryk, A.A.; Cassim, S.M.; Tate, J.A.; Baker, I.; Hoopes, P.J. Magnetic nanoparticle hyperthermia in cancer treatment. Nano Life 2010, 1, 17-32. [CrossRef]

34. Bui, T.Q.; Ngo, H.T.M.; Tran, H.T. Surface-protective assistance of ultrasound in synthesis of superparamagnetic magnetite nanoparticles and in preparation of mono-core magnetite-silica nanocomposites. J. Sci. Adv. Mater. Devices 2018, 3, 323-330. [CrossRef]

35. Shakeri-Zadeh, A.; Zareyi, H.; Sheervalilou, R.; Laurent, S.; Ghaznavi, H.; Samadian, H. Gold nanoparticle-mediated bubbles in cancer nanotechnology. J. Control. Release 2020. [CrossRef]

36. Barani, M.; Mukhtar, M.; Rahdar, A.; Sargazi, G.; Thysiadou, A.; Kyzas, G.Z. Progress in the Application of Nanoparticles and Graphene as Drug Carriers and on the Diagnosis of Brain Infections. Molecules 2021, 26, 186. [CrossRef]

37. Tsai, T.-L.; Lai, Y.-H.; Chen, H.H.; Su, W.-C. Overcoming Radiation Resistance by Iron-Platinum Metal Alloy Nanoparticles in Human Copper Transport 1-Overexpressing Cancer Cells via Mitochondrial Disturbance. Int. J. Nanomed. 2021, $16,2071$. [CrossRef]

38. Godipurge, S.; Yallappa, S.; Biradar, N.J.; Biradar, J.; Dhananjaya, B.; Hegde, G.; Jagadish, K.; Hegde, G. A facile and green strategy for the synthesis of $\mathrm{Au}, \mathrm{Ag}$ and $\mathrm{Au}-\mathrm{Ag}$ alloy nanoparticles using aerial parts of R. hypocrateriformis extract and their biological evaluation. Enzym. Microb. Technol. 2016, 95, 174-184. [CrossRef]

39. Song, X.R.; Yu, S.X.; Jin, G.X.; Wang, X.; Chen, J.; Li, J.; Liu, G.; Yang, H.H. Plant Polyphenol-Assisted Green Synthesis of Hollow CoPt Alloy Nanoparticles for Dual-Modality Imaging Guided Photothermal Therapy. Small 2016, 12, 1506-1513. [CrossRef] [PubMed]

40. Patskovsky, S.; Bergeron, E.; Rioux, D.; Simard, M.; Meunier, M. Hyperspectral reflected light microscopy of plasmonic Au/Ag alloy nanoparticles incubated as multiplex chromatic biomarkers with cancer cells. Analyst 2014, 139, 5247-5253. [CrossRef] [PubMed]

41. Karthika, V.; Arumugam, A.; Gopinath, K.; Kaleeswarran, P.; Govindarajan, M.; Alharbi, N.S.; Kadaikunnan, S.; Khaled, J.M.; Benelli, G. Guazuma ulmifolia bark-synthesized Ag, Au and Ag/Au alloy nanoparticles: Photocatalytic potential, DNA/protein interactions, anticancer activity and toxicity against 14 species of microbial pathogens. J. Photochem. Photobiol. B Biol. 2017, 167, 189-199. [CrossRef] [PubMed]

42. Li, X.; Wei, J.; Aifantis, K.E.; Fan, Y.; Feng, Q.; Cui, F.Z.; Watari, F. Current investigations into magnetic nanoparticles for biomedical applications. J. Biomed. Mater. Res. Part A 2016, 104, 1285-1296. [CrossRef] [PubMed] 
43. Zhang, H.; Liu, X.L.; Zhang, Y.F.; Gao, F.; Li, G.L.; He, Y.; Peng, M.L.; Fan, H.M. Magnetic nanoparticles based cancer therapy: Current status and applications. Sci. China Life Sci. 2018, 61, 400-414. [CrossRef] [PubMed]

44. Su, H.; Han, X.; He, L.; Deng, L.; Yu, K.; Jiang, H.; Wu, C.; Jia, Q.; Shan, S. Synthesis and characterization of magnetic dextran nanogel doped with iron oxide nanoparticles as magnetic resonance imaging probe. Int. J. Biol. Macromol. 2019, 128, 768-774. [CrossRef]

45. Peymani-Motlagh, S.M.; Sobhani-Nasab, A.; Rostami, M.; Sobati, H.; Eghbali-Arani, M.; Fasihi-Ramandi, M.; Ganjali, M.R.; Rahimi-Nasrabadi, M. Assessing the magnetic, cytotoxic and photocatalytic influence of incorporating $\mathrm{Yb} 3+$ or Pr $3+$ ions in cobalt-nickel ferrite. J. Mater. Sci. Mater. Electron. 2019, 30, 6902-6909. [CrossRef]

46. Martínez-Rodríguez, N.L.; Tavárez, S.; González-Sánchez, Z.I. In vitro toxicity assessment of zinc and nickel ferrite nanoparticles in human erythrocytes and peripheral blood mononuclear cell. Toxicol. In Vitro 2019, 57, 54-61. [CrossRef] [PubMed] 